School of Finance

University of St.Gallen

MONETARY POLICY EFFECTS ON LONG-TERM RATES AND STOCK PRICES

ANGELO RANALDO

SAMUEL REYNARD

WORKING PAPERS ON FINANCE No. 2013/22

SWISS INSTITUTE OF BANKING AND FINANCE (S/BF - HSG)

FEBRUARY 2008

THIS VERSION: NOVEMBER 2013 


\title{
Monetary Policy Effects on Long-term Rates and Stock Prices
}

\author{
Angelo Ranaldo, Samuel Reynard*
}

February 21, 2008

\begin{abstract}
This paper explains the effects of monetary policy surprises on long-term interest rates and stock prices in terms of changes in expected inflation, real interest rate and dividend growth, and relates these effects to markets' perceptions of economic shocks and Fed's information set. We analyze stock and bond futures price co-movements and relate them to Treasury Inflation-Protected Securities (TIPS) data. The sign of long-term interest rate reactions is mostly driven by changes in expected inflation. The sign of stock price reactions is mostly driven by changes in expected dividend growth, but it is also sometimes determined by changes in expected real rates. The co-movements of long-term interest rates and stock prices are determined by the co-movements of expected inflation and dividend growth. The majority of Fed's interest rate surprises are expected to be followed by negative co-movements between inflation and output. This can be due to relatively more frequent "inflation" or "supply" shocks together with Fed's private information. Most Fed's actions are perceived as reactions to economic shocks rather than true policy shocks.

JEL classification: E52; E58; E43; E44
\end{abstract}

*Swiss National Bank, Research Unit, Boersenstrasse 15, 8022 Zurich, Switzerland. Email: angelo.ranaldo@snb.ch, samuel.reynard@snb.ch. The views expressed in this paper do not necessarily reflect those of the Swiss National Bank. We thank Andreas Fischer, Michael Fleming, Refet Gürkaynak, Elmar Mertens, Paul Söderlind, as well as AEA 2008 New Orleans meetings, Bank of Portugal and SNB seminar participants, for helpful discussions and comments, and Refet Gürkaynak for sharing his dataset. 
Keywords: Monetary policy; Expectations; Long-term interest rates; Stock prices; Inflation; Real interest rate; Dividends; Economic shocks; Fed's private information 


\section{Introduction}

How do central banks' actions on a short-term interest rate affect longer-term interest rates, inflation and output? This question is at the center of monetary policy analysis, as monetary policy is nowadays usually modeled as central banks' moving a short-term interest rate as a function of macroeconomic fundamentals in order to achieve a certain inflation objective and output stabilization. This paper explains the effects of monetary policy surprises on long-term interest rates and stock prices in terms of changes in expected inflation, real interest rate and dividend growth, and relates these effects to markets' perceptions of economic shocks and Fed's information set. These issues are crucial for central bankers and macroeconomists interested in understanding the formation of expectations and the monetary policy transmission mechanism from short- to long-term interest rates and wealth, as well as for traders willing to grasp the main value drivers behind stock and bond price revisions.

The literature on financial market responses to monetary policy actions has focused on estimating average responses of either bond or stock prices taken separately, and little is known on the factors driving those responses ${ }^{1}$. The difficulty is that in order to be able to understand what causes high-frequency reactions of one variable one has to find other variables of an at least as high a frequency. Our strategy is to examine bond and stock price high-frequency co-movements and relate them to high-frequency data on Treasury Inflation-Protected Securities (TIPS) in order to relate bond and

\footnotetext{
${ }^{1}$ For example, Cochrane and Piazzesi (2002), Gürkaynak, Sack and Swanson (2005b) and Kuttner (2001) analyze bond price responses, whereas Bernanke and Kuttner (2005) analyze stock price responses. Demiralp and Jorda (2004) examine the importance of turning points and intermeeting moves for bond prices, Fleming and Piazzesi (2005) suggest that the shape of the yield curve helps explaining different maturity bond yield responses, and Gürkaynak, Sack and Swanson (2005a) show that FOMC statements help explaining different bond maturities yield and stock price movements.
} 
stock price movements to changes in expectations of inflation, real interest rate and dividend growth, and to learn about perceived causes and consequences of monetary policy surprises.

Analyzing bond and stock price co-movements provides much richer information than looking at averages, and different response patterns can be characterized. A priori, the common driver of stock and bond prices should be the real interest rate. However, there are potential correlations between expected inflation and dividend growth due to current and expected monetary policy. Together with the use of TIPS data, this allows us to learn about the influence of different expectations on bond and stock price reactions as well as the expected co-movements of monetary policy objectives, i.e. inflation and output, following policy actions.

We find that the sign of long-term interest rate reactions depends mostly on changes in expected inflation, which most of the time reflect market adjustments to perceived Fed's superior information. The sign of stock price reactions depends mostly on changes in expected dividend growth - which however cannot be disintangle from changes in expected risk premium, but it is also sometimes determined by changes in expected real rates.

Further, we find that the co-movements of long-term interest rates and stock prices in response to policy surprises are determined by the co-movements of expected inflation and dividend growth. Considering stock prices and analyzing these co-movements allows us to empirically assess different explanations suggested in the literature regarding the long-term interest rate reactions to monetary policy surprises. We compare the empirical co-movements between expected inflation and dividend (output) growth to the co-movements implied by theory. Characterizing different cases and co- 
movement patterns, we find that data support the different explanations suggested; however, there is a certain type of market reactions that current theories cannot explain. Moreover, we can quantify the frequencies of different explanations as well as the frequencies of economic shocks, and we can characterize the policy surprises' implications for the joint changes in expected inflation and output. This is an addition to the literature that has focused on changes in expected inflation.

We find that the majority of Fed's interest rate surprises are expected to be followed by negative co-movements between inflation and output. This can be due to relatively more frequent "inflation" or "supply" shocks, together with Fed private information, and could explain the price puzzle in VAR analyses. Moreover, most Fed's actions are perceived as reactions to economic shocks rather than true policy shocks.

Section 2 characterizes the joint responses of bond and stock prices to policy surprises, section 3 relates bond and stock responses to changes in expected inflation, real interest rate and dividend growth, section 4 analyzes bond and stock co-movements and relate them to perceived causes and consequences of policy surprises, and the final section concludes.

\section{The joint responses of bond and stock prices}

\subsection{Data}

Figure 3 displays the 30-minute percentage change of 10-year (TY) bond futures price and S\&P500 (S\&P) futures index to a monetary policy surprise over the period 1990-2007, and Figures 4 and 5 display these same data for upside and downside Fed Fund (FF) surprises, respectively. We use the futures contracts on the Standard \& Poor's 500 Stock Price Index quoted on the Chicago Mercantile Exchange (CME) and 
10-Year US Treasury Notes at the Chicago Board of Trade (CBOT). We extended our analysis with the 30-year US Treasury Notes futures contracts (also traded at the CBOT) and we also used different time granularities, specifically price reactions over 50-minute and daily time frames. For sake of presentation, we will show these additional findings when opportune. For more details on the data, see appendix A.

Although futures data are appropriate to capture market participants' expectations, there are at least two caveats to ponder. First, maturities on bond futures contacts do not always match those on the underling asset. The difference is however tiny. Second, the stock and bond futures contracts considered in this study have four preestablished quarterly expiration times. This implies that the time interval between expiration and FOMC dates varies and it can also contain more than one FOMC meeting. In that case, the futures price reflects the market expectation of more (scheduled) monetary policy decisions.

We measure the surprise component of the change in the federal funds rate target using federal funds futures. Federal funds futures have traded at the Chicago Board of Trade exchange since October 1988 and settle based on the average effective federal funds rate that is realized for the calendar month specified in the contract. To measure the surprise component in the FOMC release, we follow the approach of Kuttner (2001). For most announcements, the surprise is calculated as the change in the current-month futures rate scaled up by a factor related to the number of days in the month affected by the change. If the FOMC announcement occurs on the last calendar day of the month, we use the change in the next month's futures contract.

All the dates of FOMC policy decisions are listed in Appendix B. The full sample consists of 159 dates after excluding the observation of September 17, 2001 (as 
in Bernanke and Kuttner, 2005). Since February 1994 on, the FOMC has issued press releases with announcement dates and times. For the first 46 FOMC decisions (beginning of 1990 to end of 1993), the dates and related intraday times are those in Gürkaynak, Sack and Swanson (2005a). From section 3 on, we will focus on the period from the beginning of 1997 to September 2007 because of the availability of TIPS data. This sub-period includes 88 FOMC decisions.

\subsection{Characterizing bond and stock price responses}

The first interesting fact is that, from Figures 3-5, there are observations in every quadrant. The literature has focused on estimating the average response of either bond or stock prices to FF surprises, and has reported that both bond and stock prices are negatively correlated with FF surprises. This would imply observation on the bottom-left quadrant when there have been upward FF surprises and on the upperright quadrant when there have been downward FF surprises. There are however other cases, and we observe interesting co-movement patterns that could be given economic content. We will analyze these co-movements, find their causes and relate them to various expectations.

First, the average co-movement between bond and stock prices is positive; this is due to the fact that most observations are in the bottom-left and upper-right quadrants, and that bond and stock prices co-movements are positive in these two quadrants, in contrast to the two other quadrants where co-movements are negative, as discussed below. This is already a value added relative to the literature that has estimated averages responses of bonds or stocks; although the estimated average response was negative for both prices, nothing could be inferred on their co-movements (i.e. on the 
slopes). Figures 6-9 show that the co-movements are different in each quadrant: the correlation is positive in the upper-right and bottom-left quadrants, and negative in the upper-left and bottow-right quadrants. Table 1 shows the size and significance of the estimated coefficients for seven regressions where the dependent variable is the 30minute return of bond futures, and the explanatory variable is the 30-minute return of stock futures at the times of FOMC decisions. The slope coefficients are positive for the upper-right and bottom-left quadrants, and negative for the upper-left and bottom-right quadrants.

As done in the literature and for completeness, we also measure the average reaction of stock and bond markets to monetary policy surprises as

$$
\Delta p_{t}^{i}=\alpha+\beta \Delta x_{t}+\varepsilon_{t}
$$

where $\Delta x_{t}$ denotes the surprise component of the change in the federal funds rate target announced by the FOMC, $\Delta p_{t}^{i}$ denotes the change in the asset i (either stock (S) or bond (B) futures) over the intradaily or daily time intervals $t$ explained in appendix A.1. Table 2 shows that estimated betas are slightly below minus 4 for the stock index futures and around minus 0.7 for bond futures. These numbers are in line with those in the previous literature, although the bond response is more significant here; this suggests that the reaction on Futures markets overall parallels that on underlying assets.

\section{The drivers of bond and stock responses}

This section assesses the causes of bond and stock price reactions to policy surprises. 


\subsection{Concepts}

Ten-year bond yields can be expressed as

$$
i_{t}^{10 y}=-p_{t}^{B}=E_{t} \sum_{j=1}^{10}\left(\pi_{t+j}+r_{t+j}+\xi_{t+j}\right)
$$

where $\pi_{t+j}$ is the inflation rate and $\xi_{t+j}$ the term premium ${ }^{2}$. Cochrane and Piazzesi (2002) show that empirically the bond's term premium barely changes across short time intervals although it might vary within business cycles. Consistently, we assume that $\xi_{t+j}$ remains unchanged over intradaily and daily time frames. We thus assume that the expectations theory of the term structure holds and that there are no expected future excess bond return.

In order to measure change in expectations of inflation and real interest rates, we use TIPS data. The TIPS yield represents the interest rate in real terms priced by the market along with some possible risk premia. Thus, the difference between the nominal and the real yields gives us the following:

$$
i_{t}^{10 y}-r_{t}^{10}=\pi_{t}^{e}+\rho_{t}^{r}+\rho_{t}^{\pi}+\rho_{t}^{\iota},
$$

where $i_{t}^{10 y}$ is the nominal yield on a 10-year conventional Treasury, $r_{t}^{10}$ is the real yield on a 10-year indexed Treasury, $\pi^{e}$ represents the average of market participants' expected rates of future inflation for the next ten years and $\rho_{t}^{r}, \rho_{t}^{\pi}$ and $\rho_{t}^{\iota}$ represent, respectively, risk premia for changes in real interest rates, inflation and illiquidity. Those premia along with the stock risk premium (discussed below) would be negligible

\footnotetext{
${ }^{2}$ We can express $i_{t}^{10 y}=-p_{t}^{B}$, as the present value of a continuously compounded bond is $P_{0}=$ $F e^{-i t}$ where is the $F$ face value. So, by taking logs and the first difference, we get $\Delta p_{0}=-\Delta r t$. Thus bond log returns and yield changes have a one-to-one (inverse) relationship.
} 
in a risk-neutral environment. Another reason to ignore those premia is to assume that they remain unaltered in high-frequency domains. Furthermore, to check if illiquidity may have some bearing on our findings, we repeated all our tests over the sub-period 2000-2007. During this period, TIPS trading can be indisputably considered fairly liquid, especially around information events such as FOMC decisions. These additional results are perfectly consistent with those based on the whole sample. Thus, we approximate the revision in expected inflation as $\Delta i_{t}^{10 y}-\Delta r_{t}^{10} \simeq \Delta \pi_{t}^{e}$ and the revision in expected real interest rates as $\Delta r_{t}^{10}$.

Stock prices can be expressed as

$$
p_{t}^{S}=d_{t}+E_{t} \sum_{j=1}^{\infty} \rho^{j-1}\left[\Delta d_{t+j}-r_{t+j}-e_{t+j}\right],
$$

where $d_{t}$ is real dividend, $r_{t}$ is real interest rate, and $e_{t}$ is stocks risk premium or excess return. $\rho$ comes out of a log-linear approximation procedure and is a number a little smaller than one (0.9962 in the empirical work of Campbell and Ammer, 1993). By taking the first difference of price changes and adding the revisions in expected real interest rates $\Delta r_{t}^{10}$ that we recover from the TIPS data, we obtain an appoximation of the expected dividend growth net of the expected equity risk premium. We will henceforth refer to the net dividend growth (using the acronym "NDG"):

$$
\Delta p_{t}^{S}+\Delta r_{t}^{10} \simeq \Delta E_{t} \sum_{j=1}^{\infty} \rho^{j-1}\left[\Delta d_{t+j}-e_{t+j}\right]
$$

Appendix A provides additional details on data computations, and appendix B shows data on changes in expected real rates, inflation and net dividend growth for each FOMC date. 


\subsection{Empirical analysis of asset value drivers}

Tables 3 displays averages of the different determinants in each quadrant. More specifically, it shows the average values of the revisions in expectation on inflation (DEINFL), real interest rates (DERR) and net dividend growth (NDG), conditional on the joint stock and bond market reactions to (non-zero) monetary policy surprises. Two main patterns clearly emerge.

First, bond price reactions are primarily determined by changes in expected inflation. Bond yields go up when expected inflation increases, and down when expected inflation decreases. Real interest rates usually move in the same direction as the surprise, but with smaller amplitude than changes in expected inflation. Thus, changes in expected inflation are the dominant factor for the sign of bond reactions to FF surprises. Similar results are obtained when the sample is split in two instead of four parts, i.e. when upward and downward bond price movements are examined separately.

Second, changes in stock prices are mostly driven by changes in net dividend growth, supporting Bernanke and Kuttner (2005) results. Changes in NDG are higher (and always higher than real rate changes) when stock prices increase than when the latter decrease. When stock prices decrease, NDG changes are either negative or at least not higher than changes in real rate (with the only exception of NGDd in the "sp down / ty up" case when FF decreases, where the decrease in NDG is smaller in absolute value than the decrease in DEER; however NDG 30m follows the rule); note that in cases where the FF decreases, it is the real rate change that sometimes determines the sign of stock price change. Again, similar results are obtained when the sample is split in two instead of four parts. 
We further analyze the market reaction to monetary policy surprises with two additional methods: first, we calculate the correlations between asset returns and their value drivers; second, we perform a regression analysis. Table 4 shows the correlation matrices between stock futures returns ("SP"), bond futures returns (either 10-year or 30-year US Treasury Notes denoted by "TY" and "US", respectively) and their value drivers, i.e. revisions on expected inflation (DEINFL), real interest rates (DERR) and net dividend growth (NDG). The finding discernible in Table 4 is that the linkages between asset returns and their value factors are in line with those implied by the present value formulas. Bond returns are negatively related to revisions in expected inflation and real interest rates while stock returns are positively related to net dividend growth and negatively to real rates. The positive correlation between net dividend growth and real rates can be explained by standard mechanisms in the consumption Euler equation.

The main idea behind the regression analysis is to estimate the contribution of the revisions in expectations to the revelation process triggered by a monetary policy surprise. Table 5 shows the regression results where the dependent variable is the daily return of futures prices on the S\&P index, 10-year and 30-year US Treasury Notes. The explanatory variables are a constant, revisions in expectations on real interest rates ("DERR") and expected inflation ("DEINFL") for bonds, and on net dividend growth ("NDG") for stocks. The explanatory variables are used one after the other. This step-by-step procedure allows us to observe the contribution of each individual variable and to perform the variance decomposition. The LS regression for bonds are:

$$
\Delta p_{t, i}^{B}=\alpha+\beta_{1} \Delta r_{t}^{e}+\varepsilon_{t}
$$




$$
\begin{gathered}
\Delta p_{t, i}^{B}=\alpha+\beta_{2} \Delta \pi_{t}^{e}+\varepsilon_{t} \\
\Delta p_{t, i}^{B}=\alpha+\beta_{1} \Delta r_{t}^{e}+\beta_{2} \Delta \pi_{t}^{e}+\varepsilon_{t}
\end{gathered}
$$

Where $\Delta p_{t, i}^{B}$ denotes the change in the asset i (either futures contracts on 10-Year and 30-year US Treasury Notes) in time t, $\Delta r_{t}^{e}$ represents the revision in real rates, $\Delta \pi_{t}^{e}$ represents the proxy for the revision in expected inflation, and $\beta_{1}$ and $\beta_{2}$ are the related coefficients to gauge market reaction. $\varepsilon_{t}$ is the regression residual.

The LS regression for stocks are:

$$
\begin{aligned}
& \Delta p_{t}^{S}=\alpha+\beta_{1} \Delta r_{t}^{e}+\varepsilon_{t} \\
& \Delta p_{t}^{S}=\alpha+\beta_{2} \Delta \delta_{t}^{e}+\varepsilon_{t}
\end{aligned}
$$

Where $\Delta p_{t}^{S}$ denotes the change in the stock futures index in time $\mathrm{t}$ and $\Delta \delta_{t}^{e}$ represents the proxy for the revision in expected net dividend growth. For stocks, we do not consider the joint regression of $\Delta r_{t}^{e}$ and $\Delta \delta_{t}^{e}$ because (1) the results would be biased by collinearity, and (2) $\Delta r_{t}^{e}$ has no significant contribution.

The main findings are that changes in expectations on real interest rates and inflation evenly contribute to the variance of bond price revisions, although the variance decomposition indicates that the bond return variance appears slightly more related to revisions in real rates. On the other hand, the revision in expected real rates has virtually no bearing on the stock reprising process due to monetary policy surprises. The main stock market reaction is driven by changes in expected net dividend growth. 
Differences between the averages presented in table 3 and variance decomposition results can be understood as follows. Table 3 represents averages conditional on the sign of the FF surprise and contional on bond or stock prices going up or down, whereas variance decomposition regressions represent unconditional results. We see in table 3 that expected real rates increase when the FF rate increases and vice versa. That means that long-term rates are also influenced by movements in the real rate (in the same direction than the FF rate), but for a given sign of the FF movement, the direction of change in long-term yield is determined by the direction of inflation

expectation change. Idem (but with dividends) for stocks. Real rates go in different directions (consistent with bonds) when the whole sample is considered; thus interest rate smoothing perception seems important. Same results if look at bonds or stocks separately.

\section{Bond/stock price co-movements and monetary policy}

\subsection{Determinants of bond/stock price co-movements}

[co-movement inside each quadrant is not known a priori, and can support or reject theory; we find that it supports]

The questions we address in this section are which factors determine the joint reactions of stock and bond prices, and what can we learn from these co-movements about perceived monetary policy and economic shocks. As before, we proceed in two ways. First, we look at correlations between the joint stock and bond market reaction and their value drivers taken individually and jointly. As a measure of joint market reaction, we take the multiplication of stock and bond returns. Table 6 shows the correlation matrices between the joint stock and bond futures returns 
(" $\Delta$ sp. $\Delta$ ty"), individual value drivers $(\Delta I, \Delta r$ and $\Delta d$ which means revisions in expected inflation, real interest rates and net dividend growth, respectively) and their combinations $(\Delta I . \Delta r, \Delta r . \Delta \delta, \Delta \pi . \Delta \delta$ and $\Delta \pi . \Delta r . \Delta \delta$ ) based on 30-minute and daily time intervals. From these correlations we see that co-movements in stock and bond prices are strongly negatively correlated with co-movements in expected inflation and NDG. Expected inflation and NDG are not correlated with each other over the whole sample, but the correlations (not shown in the tables) between these two variables differ between quadrants: the correlation is -.38 in the bottom-left and upper-right quadrants, and +.41 in the upper-left and bottom-right quadrants, thus in line with the explanation that the co-movements between these two variables drive bond and stock price co-movements.

Second, we perform a regression analysis. The main idea is to assess to what extent the joint revision of expected inflation and net dividend growth at monetary policy announcements can explain the joint reaction of stock and bond markets. Two regression methods are used. On the one hand, we perform LS regressions where the explained variable is the intradaily or daily stock futures return multiplied by the simultaneous bond futures return, the explanatory variables is a constant and the multiplication of the revision in expected inflation and net dividend growth.

$$
\Delta p_{t}^{S} \cdot \Delta p_{t, i}^{B}=\alpha+\beta \Delta \pi_{t}^{e} \Delta \delta_{t}^{e}+\varepsilon_{t}
$$

As above, $\Delta p_{t, i}^{B}$ and $\Delta p_{t}^{S}$ denote bond and stock returns and $\Delta \pi_{t}^{e}$ and $\Delta \delta_{t}^{e}$ mean revisions in expected inflation and net dividend growth.

On the other hand, we estimate a Probit regression where the dependent variable is equal to 1 if stock return multiplied to bond return is positive, 0 otherwise, and the 
explanatory variable has a binary value that is 1 if the multiplication of the proxies for the revisions in expectations on inflation and net dividend growth is positive, zero otherwise. The use of binary explained and explanatory variables should show whether the mere direction in revised expectations determines the direction of the joint market reaction. Thus, we have

$$
y_{t}=\alpha+\beta x_{t}+\varepsilon_{t}
$$

where $y_{t}$ is equal 1 if $\Delta p_{t}^{S} . \Delta p_{t, i}^{B}$ positive, 0 otherwise; $x_{t}$ is equal 1 if $\Delta \pi_{t}^{e} . \Delta \delta_{t}^{e}$ positive, 0 otherwise.

The main regression results are in Table 7. As for the correlation analysis, the regression approach shows that co-movement between bond and stock prices is driven by co-movements between expected inflation and dividend growth.

\subsection{Policy interpretation}

Bond and stock price co-movements provide useful information on what drives market reactions at a given point in time, and how markets perceive the causes and consequences of monetary policy actions. The four different bond/stock price sign reaction combinations can be related to the literature in the following way.

Consider the case where the Fed Fund (FF) surprise is positive (a symmetric reasoning can be applied in the case of a negative FF surprise). Romer and Romer (2000) argue that in that case, an increase in long-term yields (i.e. a decrease in bond prices) can be due to Fed's private information. A surprise increase in the FF rate means that the Fed has information that inflation will increase by more than what people had expected, thus inflation expectations increase and bond prices decline. This would 
correspond to our bottom-left and bottow-right quadrants. These two quadrants however display different relationships. In the bottom-right quadrant, bond prices decline whereas stock prices increase, and there is a negative relationship between both prices, i.e. the more bond prices decline, the more stock prices increase. In a New-Keynesian (NK) framework, this could be the consequence of a "demand" shock. As markets interpret the increase in FF signaling information of higher output and inflation, long-term yields increase and stock prices increase as well given that dividend growth are expected to increase. The larger the shock, the more long-term rates increase (due to higher inflation) and stock prices increase (due to higher expected output growth). These types of shocks represent 20 percent of observations (for both surprise increases and decreases in FF).

In the bottom-left quadrant in contrast, both bond and stock prices go down, and there is a positive relationship between these two prices, i.e. the more bonds go down, the more stocks decline. In a NK framework, this could be the consequence of an "inflation" or "supply" shock. As markets interpret the increase in FF signaling information of higher inflation, long-term yields increase. However, stock price decrease as higher inflation means that the Fed is going to tighten policy; thus expected real rate increase, and dividend growth decreases, or at least increases slower (case of a positive shock that affects inflation more than output). The positive relationship between stock and bond prices means that the higher the inflation shock, the more negative output growth is expected to react as a result of a tighter monetary policy aiming at curbing inflation. These types of shocks are the most frequent with 37 percent of observations.

There are however cases when long-term rates decrease after a positive FF surprise. 
Ellingsen and Söderström $(2001,2005)$ replicate these facts within a NK framework where the central bank decreases its inflation target or increases its weight on inflation relative to output stabilization. In that case, the lower the new inflation target, the lower inflation expectations and thus long-term rates, and the lower output growth given a stronger policy tightening. These mechanisms would thus match well with the negative relationship between bond and stock prices in the upper-left quadrant. These types of shocks represent 17 percent of observations and can be interpreted as true policy shocks.

These theories can however not explain observations in the upper-right quadrant (in case of a positive FF surprise), which represent 19 percent of observations. There, both bond and stock prices increase. Clues of what happens in that quadrant can be found in financial newspaper interpretations of market reactions. In these cases, financial markets usually interpret Fed moves as decisive actions to dampen inflation, and thus the Fed is seen as being through increasing interest rates for the time being. This thus decreases expected inflation and long-term yields and increase expected dividends and stock prices as the next Fed's moves are expected to be on the downside.

At the opposite, observations in the bottom-left quadrant, i.e. when both bond and stock prices decrease, are interpreted (by newspapers reporting financial analysts' opinions) as being among the first of a series of $\mathrm{FF}$ increases. In these cases, markets interpret the surprise increase in FF as indicating that further upward moves would be necessary to curb inflation. Thus long-term yields increase and stock price decrease as further monetary tightening are expected to depress output growth. Thus these market expectations of further increases can be related to the interest rate smoothing behavior of the Fed (and of central banks in general). 
Observations in the upper-left quadrant (i.e. when stock prices decrease and bond prices increase) occur when the Fed acts to curb growth before inflation has even occurred. Thus expected dividend growth and inflation decrease with the policy tightening.

[However, the relationship between expected inflation and output is positive when the Fed reacts to output growth concerns or tries to pre-empt inflation developments.]

Reconciling press reports' interpretations with what could be inferred from a NK framework is left for further work.

\section{Conclusions}

Analyzing bond and stock price co-movements, together with TIPS data, thus helps understanding what drives these prices and relating the effects of monetary policy on long-term yields and stocks to expected inflation and output.

Assessing whether systematic relationships between market responses and states of the economy can be uncovered is left for future work. 


\section{Appendix A: Data sources and computations}

\section{A.1. High Frequency Bond and Stock Data}

To measure the market reaction to FOMC releases, we use the futures contracts on the Standard \& Poor's 500 Stock Price Index quoted on the Chicago Mercantile Exchange (CME) and 10-Year and 30-year US Treasury Notes at the Chicago Board of Trade (CBOT). We obtained the database from tickdata.com. The data contain the time stamp to the nearest second and transaction price of all trades that occurred from January 1, 1990 to September 30, 2007.

We use the most actively traded nearest-to-maturity or cheapest-to-delivery futures contract, switching to the next-maturity contract five days before expiration. We organize our data in 5-minute intervals. If no trades occur in a given 5-minute interval, we copy down the last trading price in the previous time interval.

After matching the intraday time-stamp of the FOMC decisions with the intraday price records, we calculate the percentage price changes over 30-minute, 50-minute and daily periods. For the 30-minute (50-minute) time frame, we consider the price 5 (10) minutes before and 25 (40) minutes after the monetary announcements. We decided to take 50 minutes rather 1 hour since several times the FOMC decision has been taken at 2:15 ET. Thus, the 50-minute time frame allows us to conveniently measure the price change before the settlement price. Daily price changes are based on close-to-close returns. In few occasions, intraday data where not available since monetary decisions were taken outside CBOT or CME trading hours. In these circumstances, we use daily price changes. This happened six times for the S\&P futures and twice for the Treasury Yield futures. These numbers are marked in bold in appendix 
B. The inclusion or exclusion of these observations leaves our results unchanged

\section{A.2. TIPS}

Data on interest rates are from the Federal Reserve Bank of St. Louis FRED ${ }^{\circledR}$ database. From there, we obtained data on the 10-Year Treasury Constant Maturity Rates and TIPS. Our dataset on TIPS goes from the beginning of 1997 to the end of September 2007. From January 1997 to the end of 2002, we construct a continuous time series by assembling a sequence of six TIPS assets. We used the on-the-run criterion to switch from one security to the next one, i.e. we considered the most recent issued instrument. Since the beginning of 2003, we use the TIPS index based on the Constant Maturity construction.

\begin{tabular}{llll} 
FRED ID & Title & From & To \\
\hline DTP10J07 & 10 -Year 3-3/8\% Treasury Inflation-Indexed Note & 29.01 .1997 & 12.01 .1998 \\
DTP10J08 & 10 -Year 3-5/8\% Treasury Inflation-Indexed Note & 13.01 .1998 & 06.01 .1999 \\
DTP10J09 & 10 -Year 3-7/8\% Treasury Inflation-Indexed Note & 07.01 .1999 & 17.01 .2000 \\
DTP10J10 & 10 -Year 4-1/4\% Inflation-Indexed Note & 18.01 .2000 & 10.01 .2001 \\
DTP10J11 & 10 -Year 3-1/2\% Treasury Inflation-Indexed Note & 11.01 .2001 & 09.01 .2002 \\
DTP10J12 & 10 -Year 3-3/8\% Treasury Inflation-Indexed Note & 10.01 .2002 & 01.01 .2003 \\
DFII10 & 10 -Year Treasury Inflation-Indexed Security, Constant Maturity & 02.01 .2003 & 28.09 .2007
\end{tabular}

FIG. 1. 


\section{Appendix B: Fed decisions and market reactions}

This table shows the federal funds target rates in levels ("level") and in changes ("change"), monetary policy surprises calculated on the basis of the federal funds futures appropriately re-scaled ("Surprise"), the 30-minute price reactions in $\%$ of futures contracts on the S\&P 500 index and 10-Year US Treasury Notes ("SP 30m" and "TY 30m"). From 1997, it also shows the estimations for the revisions in expectations on inflation ("DEINFL"), on real rates ("DERR") and on net dividend growth ("NDG") on a daily basis. Bold numbers mean that intradaily data were not available on that date and these are replaced with daily figures. 
\begin{tabular}{lccccc} 
date & Level & Change & Surprise & SP 30m & TY 30m \\
\hline 08.02 .1990 & 8.25 & 0 & -0.01 & -0.30 & -0.06
\end{tabular}

\begin{tabular}{lllllll}
\hline 08.02 .1990 & 8.25 & 0 & -0.01 & -0.30 & -0.06 \\
28.03 .1990 & 8.25 & 0 & 0.00 & -0.22 & 0.00
\end{tabular}

$\begin{array}{llllll}28.03 .1990 & 8.25 & 0 & 0.00 & -0.22 & 0.00 \\ 16.05 .1990 & 8.25 & 0 & 0.00 & 0.31 & 0.07\end{array}$

$\begin{array}{llllll}16.05 .1990 & 8.25 & 0 & 0.00 & 0.31 & 0.07 \\ 05.07 .1990 & 8.25 & 0 & 0.00 & -0.11 & -0.06\end{array}$

$\begin{array}{lccccc}13.07 .1990 & 8 & -0.25 & -0.14 & -0.17 & -0.10\end{array}$

$\begin{array}{cccccc}22.08 .1990 & 8 & 0 & 0.00 & 0.03 & 0.10\end{array}$

$\begin{array}{llllll}03.10 .1990 & 8 & 0 & 0.01 & 0.14 & 0.13\end{array}$

$\begin{array}{llllll}29.10 .1990 & 7.75 & -0.25 & -0.03 & -0.24 & -0.03\end{array}$

$\begin{array}{llllll}14.11 .1990 & 7.5 & -0.25 & 0.02 & -0.03 & -0.06\end{array}$

$\begin{array}{llllll}07.12 .1990 & 7.25 & -0.25 & -0.09 & -0.08 & 0.00\end{array}$

$\begin{array}{llllll}18.12 .1990 & 7.25 & 0 & -0.22 & 0.92 & \mathbf{0 . 0 0}\end{array}$

$\begin{array}{cccccc}08.01 .1991 & 7 & 0 & -0.14 & 0.46 & 0.44\end{array}$

$\begin{array}{llllll}01.02 .1991 & 6.25 & -0.5 & -0.07 & \mathbf{- 0 . 1 8} & -0.06\end{array}$

$\begin{array}{llllll}07.02 .1991 & 6.25 & 0 & 0.00 & -0.04 & 0.00\end{array}$

$\begin{array}{llllll}08.03 .1991 & 6 & -0.25 & -0.03 & 0.11 & 0.16\end{array}$

$\begin{array}{cccccc}27.03 .1991 & 6 & 0 & -0.02 & 0.25 & 0.06\end{array}$

$\begin{array}{llllll}30.04 .1991 & 5.75 & -0.25 & -0.18 & 0.78 & 0.38\end{array}$

$\begin{array}{llllll}15.05 .1991 & 5.75 & 0 & 0.02 & 0.09 & -0.06\end{array}$

$\begin{array}{llllll}05.07 .1991 & 5.75 & 0 & 0.00 & -0.13 & -0.16\end{array}$

$\begin{array}{llllll}06.08 .1991 & 5.5 & -0.25 & -0.19 & 0.61 & 0.25\end{array}$

$\begin{array}{cccccc}21.08 .1991 & 5.5 & 0 & 0.12 & -0.05 & -0.03\end{array}$

$\begin{array}{llllll}13.09 .1991 & 5.25 & -0.25 & -0.05 & \mathbf{- 0 . 0 5} & 0.00\end{array}$

$\begin{array}{llllll}02.10 .1991 & 5.25 & 0 & -0.01 & -0.15 & -0.03\end{array}$

$\begin{array}{llllll}30.10 .1991 & 5.25 & 0 & -0.03 & -0.04 & 0.00\end{array}$

$\begin{array}{llllll}06.11 .1991 & 4.75 & -0.25 & -0.10 & \mathbf{0 . 0 0} & 0.21\end{array}$

$\begin{array}{llllll}06.12 .1991 & 4.5 & -0.25 & 0.00 & -0.03 & -0.09\end{array}$

$\begin{array}{llllll}18.12 .1991 & 4.5 & 0 & 0.05 & -0.03 & 0.00\end{array}$

$\begin{array}{llllll}20.12 .1991 & 4 & -0.5 & -0.37 & \mathbf{0 . 0 0} & 0.48\end{array}$

$\begin{array}{llllll}06.02 .1992 & 4 & 0 & 0.01 & 0.00 & 0.03\end{array}$

$\begin{array}{llllll}01.04 .1992 & 4 & 0 & 0.01 & -0.09 & 0.03\end{array}$

$\begin{array}{llllll}09.04 .1992 & 3.75 & -0.25 & -0.21 & 0.73 & 0.24\end{array}$

$\begin{array}{llllll}20.05 .1992 & 3.75 & 0 & 0.00 & 0.01 & 0.06\end{array}$

$\begin{array}{llllll}02.07 .1992 & 3.25 & -0.5 & -0.09 & \mathbf{0 . 0 6} & -0.15\end{array}$

$\begin{array}{llllll}19.08 .1992 & 3.25 & 0 & 0.03 & 0.01 & 0.03\end{array}$

$\begin{array}{cccccc}04.09 .1992 & 3 & -0.25 & 0.00 & 0.02 & -0.03\end{array}$

$\begin{array}{llllll}07.10 .1992 & 3 & 0 & 0.00 & -0.01 & -0.06\end{array}$

$\begin{array}{llllll}18.11 .1992 & 3 & 0 & -0.05 & 0.37 & -0.03\end{array}$

$\begin{array}{llllll}23.12 .1992 & 3 & 0 & 0.04 & -0.14 & 0.00\end{array}$

$\begin{array}{llllll}04.02 .1993 & 3 & 0 & 0.00 & -0.08 & 0.00\end{array}$

$\begin{array}{rrrrrr}24.03 .1993 & 3 & 0 & 0.00 & -0.04 & 0.00 \\ 19.05 .1993 & 3 & 0 & -0.03 & 0.26 & 0.17\end{array}$

$\begin{array}{lll}-0.03 & 0.26 & 0.17\end{array}$

$\begin{array}{lll}0.03 & 0.18 & 0.00\end{array}$

$\begin{array}{llllll}18.08 .1993 & 3 & 0 & 0.00 & -0.14 & -0.05\end{array}$

$\begin{array}{llllll}22.09 .1993 & 3 & 0 & 0.00 & -0.02 & -0.05\end{array}$

$\begin{array}{llllll}17.11 .1993 & 3 & 0 & 0.02 & -0.12 & 0.11\end{array}$

$\begin{array}{llllll}22.12 .1993 & 3 & 0 & 0.00 & -0.05 & -0.03\end{array}$

$\begin{array}{llllll}04.02 .1994 & 3.25 & 0.25 & 0.16 & -0.77 & -0.50\end{array}$

$\begin{array}{cccccc}22.03 .1994 & 3.5 & 0.25 & 0.00 & 0.28 & 0.38\end{array}$

$\begin{array}{llllll}18.04 .1994 & 3.75 & 0.25 & 0.15 & -0.80 & -0.45\end{array}$

$\begin{array}{llllll}17.05 .1994 & 4.25 & 0.5 & 0.11 & 0.43 & 0.57\end{array}$

$\begin{array}{llllll}06.07 .1994 & 4.25 & 0 & -0.05 & -0.02 & -0.03\end{array}$

$\begin{array}{llllll}16.08 .1994 & 4.75 & 0.5 & 0.12 & -0.32 & 0.15\end{array}$

$\begin{array}{cccccc}27.09 .1994 & 4.75 & 0 & -0.09 & -0.26 & -0.22 \\ 15.11 .1994 & 5.5 & 0.75 & 0.12 & -0.91 & 0.19\end{array}$

$\begin{array}{llllll}15.11 .1994 & 5.5 & 0.75 & 0.12 & -0.91 & 0.19\end{array}$

$\begin{array}{cccccc}20.12 .1994 & 5.5 & 0 & -0.23 & 0.01 & -0.06 \\ 01.02 .1995 & 6 & 0.5 & 0.06 & -0.19 & -0.15\end{array}$

$\begin{array}{cccccc}01.02 .1995 & 6 & 0.5 & 0.06 & -0.19 & -0.15 \\ 28.03 .1995 & 6 & 0 & -0.01 & -0.03 & -0.06\end{array}$

$\begin{array}{llllll}23.05 .1995 & 6 & 0 & 0.00 & 0.19 & 0.00\end{array}$

$\begin{array}{llllll}06.07 .1995 & 5.75 & -0.25 & -0.11 & 0.22 & 0.93\end{array}$

$\begin{array}{llllll}22.08 .1995 & 5.75 & 0 & 0.03 & -0.22 & -0.20\end{array}$

$\begin{array}{llllll}26.09 .1995 & 5.75 & 0 & 0.03 & -0.32 & -0.29\end{array}$

$\begin{array}{cccccc}15.11 .1995 & 5.75 & 0 & 0.04 & -0.05 & -0.17 \\ 19.12 .1995 & 5.5 & -0.25 & -0.09 & 0.38 & 0.19\end{array}$

$\begin{array}{llllll}19.12 .1995 & 5.5 & -0.25 & -0.09 & 0.38 & 0.19\end{array}$

$\begin{array}{llllll}31.01 .1996 & 5.25 & -0.25 & -0.03 & 0.21 & 0.14\end{array}$

$\begin{array}{llllll}26.03 .1996 & 5.25 & 0 & 0.01 & 0.12 & -0.17\end{array}$

$\begin{array}{llllll}21.05 .1996 & 5.25 & 0 & 0.00 & -0.25 & -0.09\end{array}$

$\begin{array}{llllll}03.07 .1996 & 5.25 & 0 & -0.07 & 0.01 & 0.09\end{array}$

$\begin{array}{llllll}20.08 .1996 & 5.25 & 0 & -0.03 & -0.04 & -0.09\end{array}$

$\begin{array}{llllll}24.09 .1996 & 5.25 & 0 & -0.12 & -0.12 & 0.15\end{array}$

$\begin{array}{llllll}13.11 .1996 & 5.25 & 0 & -0.02 & 0.29 & 0.14\end{array}$

$\begin{array}{llllll}17.12 .1996 & 5.25 & 0 & 0.01 & -0.25 & -0.06\end{array}$ \begin{tabular}{lcccccccc} 
date & Level & Change & Surprise & SP 30m & TY 30m & DEINFL & DERR & NDG \\
\hline 05.02 .1997 & 5.25 & 0 & -0.04 & -0.48 & -0.23 & 0.64 & 0.00 & -1.72
\end{tabular}

$\begin{array}{lllllllll}25.03 .1997 & 5.5 & 0.25 & 0.04 & -0.44 & -0.26 & -0.31 & 1.15 & 0.16\end{array}$

$\begin{array}{ccccccccc}25.03 .1997 & 5.5 & 0.25 & 0.04 & -0.44 & -0.26 & -0.31 & 1.15 & 0.16 \\ 20.05 .1997 & 5.5 & 0 & -0.10 & 0.45 & 0.12 & -0.32 & 0.00 & 1.10\end{array}$

$\begin{array}{lllllllll}02.07 .1997 & 5.5 & 0 & -0.02 & 0.31 & 0.12 & -1.06 & 0.00 & 1.73\end{array}$

$\begin{array}{lllllllll}19.08 .1997 & 5.5 & 0 & 0.00 & -0.54 & -0.11 & 0.00 & 0.00 & 1.33\end{array}$

$\begin{array}{lllllllll}30.09 .1997 & 5.5 & 0 & 0.00 & -0.22 & -0.06 & 1.21 & -0.28 & -1.14\end{array}$

$\begin{array}{lllllllll}12.11 .1997 & 5.5 & 0 & -0.04 & -0.43 & 0.22 & -0.84 & 0.00 & -1.89\end{array}$

$\begin{array}{lllllllll}16.12 .1997 & 5.5 & 0 & 0.00 & -0.20 & 0.00 & -1.81 & 0.84 & 1.51\end{array}$

$\begin{array}{lllllllll}04.02 .1998 & 5.5 & 0 & 0.00 & -0.38 & -0.11 & 1.05 & -0.27 & -0.37\end{array}$

$\begin{array}{lllllllll}31.03 .1998 & 5.5 & 0 & -0.01 & 0.04 & 0.00 & -2.54 & 0.00 & 0.74\end{array}$

$\begin{array}{lllllllll}19.05 .1998 & 5.5 & 0 & -0.03 & -0.29 & \mathbf{- 0 . 0 3} & 0.53 & 0.00 & 0.59\end{array}$

$\begin{array}{lllllllll}01.07 .1998 & 5.5 & 0 & -0.01 & -0.02 & -0.03 & 0.00 & 0.00 & 1.23\end{array}$

$\begin{array}{lllllllll}18.08 .1998 & 5.5 & 0 & 0.01 & \mathbf{0 . 1 8} & 0.03 & 0.63 & 0.00 & 1.96\end{array}$

$\begin{array}{lllllllll}29.09 .1998 & 5.25 & -0.25 & 0.05 & -1.33 & 0.13 & 0.00 & -0.56 & -1.02\end{array}$

$\begin{array}{lllllllll}15.10 .1998 & 5 & -0.25 & -0.24 & 2.04 & 0.70 & -1.18 & 0.27 & 5.53\end{array}$

$\begin{array}{lllllllll}17.11 .1998 & 4.75 & -0.25 & -0.07 & 0.75 & -0.13 & 4.85 & -0.79 & -0.79\end{array}$

$\begin{array}{ccccccccc}22.12 .1998 & 4.75 & 0 & 0.00 & -0.22 & -0.03 & 4.71 & 0.53 & 0.72\end{array}$

$\begin{array}{lllllllll}03.02 .1999 & 4.75 & 0 & 0.01 & -0.02 & -0.11 & 3.85 & 0.00 & 0.78\end{array}$

$\begin{array}{lllllllll}30.03 .1999 & 4.75 & 0 & -0.01 & -0.24 & 0.08 & -5.11 & 0.00 & 0.38\end{array}$

$\begin{array}{lllllllll}18.05 .1999 & 4.75 & 0 & -0.01 & -1.25 & -0.58 & -0.54 & 0.79 & 0.61\end{array}$

$\begin{array}{lcccccccc}30.06 .1999 & 5 & 0.25 & -0.03 & 1.58 & 0.54 & -6.25 & 0.00 & 2.66\end{array}$

$\begin{array}{lllllllll}24.08 .1999 & 5.25 & 0.25 & 0.04 & \mathbf{0 . 2 6} & 0.00 & -2.14 & 0.00 & 0.73\end{array}$

$\begin{array}{lllllllll}05.10 .1999 & 5.25 & 0 & -0.04 & -1.40 & -0.41 & 3.19 & 0.25 & -0.58\end{array}$

$\begin{array}{lllllllll}16.11 .1999 & 5.5 & 0.25 & 0.08 & -0.01 & -0.23 & 1.08 & 0.25 & 2.07\end{array}$

$\begin{array}{llcllllll}21.12 .1999 & 5.5 & 0 & 0.02 & \mathbf{0 . 5 7} & -0.26 & 0.98 & 0.00 & 1.20\end{array}$

$\begin{array}{lllllllll}02.02 .2000 & 5.75 & 0.25 & -0.06 & -0.21 & -0.26 & 0.43 & -0.70 & -0.66\end{array}$

$\begin{array}{lllllllll}21.03 .2000 & 6 & 0.25 & -0.05 & 0.10 & 0.06 & -2.48 & 0.00 & 2.21\end{array}$

$\begin{array}{lllllllll}16.05 .2000 & 6.5 & 0.5 & 0.04 & \mathbf{- 0 . 6 8} & -0.23 & -1.76 & 0.00 & 1.21\end{array}$

$\begin{array}{lllllllll}28.06 .2000 & 6.5 & 0 & -0.03 & 0.11 & 0.02 & 0.50 & 0.00 & -0.10\end{array}$

$\begin{array}{lllllllll}22.08 .2000 & 6.5 & 0 & -0.02 & -0.20 & 0.00 & 0.00 & -0.25 & -0.14\end{array}$

$\begin{array}{lllllllll}03.10 .2000 & 6.5 & 0 & 0.00 & -0.30 & -0.19 & 2.15 & 0.00 & -1.31\end{array}$

$\begin{array}{lllllllll}15.11 .2000 & 6.5 & 0 & -0.01 & -0.82 & 0.11 & -2.09 & 0.00 & 0.46\end{array}$

$\begin{array}{lllllllll}19.12 .2000 & 6.5 & 0 & 0.07 & \mathbf{- 0 . 7 0} & -0.07 & 1.42 & 0.00 & -2.42\end{array}$

$\begin{array}{lllllllll}03.01 .2001 & 6 & -0.5 & -0.39 & 4.75 & -0.74 & 14.62 & 0.83 & 4.06\end{array}$

$\begin{array}{lllllllll}31.01 .2001 & 5.5 & -0.5 & 0.04 & -0.12 & -0.03 & -2.98 & 0.00 & -0.24\end{array}$

$\begin{array}{lllllllll}20.03 .2001 & 5 & -0.5 & 0.07 & -0.80 & 0.21 & -3.95 & 0.61 & -1.50\end{array}$

$\begin{array}{lllllllll}18.04 .2001 & 4.5 & -0.5 & -0.44 & 2.11 & 0.50 & 1.68 & -2.92 & 1.76\end{array}$

$\begin{array}{lllllllll}15.05 .2001 & 4 & -0.5 & -0.10 & 0.72 & 0.09 & -0.45 & 1.55 & 1.59\end{array}$

$\begin{array}{lllllllll}27.06 .2001 & 3.75 & -0.25 & 0.11 & -0.49 & 0.01 & -0.51 & 0.91 & 0.65\end{array}$

$\begin{array}{lllllllll}21.08 .2001 & 3.5 & -0.25 & 0.02 & -0.65 & -0.03 & 4.76 & -3.20 & -4.77\end{array}$

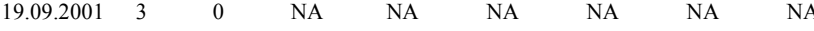

$\begin{array}{lllllllll}02.10 .2001 & 2.5 & -0.5 & -0.04 & -0.68 & 0.10 & 1.43 & -1.27 & 0.16\end{array}$

$\begin{array}{lcccccccc}06.11 .2001 & 2 & -0.5 & -0.15 & 0.41 & 0.27 & -0.76 & 0.00 & 1.75\end{array}$

$\begin{array}{lllllllll}11.12 .2001 & 1.75 & -0.25 & -0.01 & 0.38 & 0.25 & -2.53 & 0.00 & 0.17\end{array}$

$\begin{array}{lllllllll}30.01 .2002 & 1.75 & 0 & 0.03 & 0.00 & 0.15 & 1.28 & -0.58 & 0.81\end{array}$

$\begin{array}{lllllllll}19.03 .2002 & 1.75 & 0 & -0.03 & -0.17 & 0.23 & 0.52 & 0.00 & 0.48\end{array}$

$\begin{array}{lllllllll}07.05 .2002 & 1.75 & 0 & 0.01 & -0.33 & 0.12 & 0.50 & -0.65 & -0.96\end{array}$

$\begin{array}{lllllllll}26.06 .2002 & 1.75 & 0 & 0.00 & -0.50 & -0.04 & -0.56 & -3.86 & -3.01\end{array}$

$\begin{array}{lllllllll}13.08 .2002 & 1.75 & 0 & 0.04 & -0.24 & 0.51 & -5.68 & 0.00 & -1.35\end{array}$

$\begin{array}{lllllllll}24.09 .2002 & 1.75 & 0 & 0.02 & -0.76 & 0.12 & 1.28 & -1.40 & -2.90\end{array}$

$\begin{array}{lllllllll}06.11 .2002 & 1.25 & -0.5 & -0.20 & -0.31 & 0.33 & -0.60 & 0.00 & 1.47\end{array}$

$\begin{array}{lllllllll}10.12 .2002 & 1.25 & 0 & 0.00 & -0.28 & -0.08 & -0.62 & 0.41 & 1.83\end{array}$

$\begin{array}{lllllllll}29.01 .2003 & 1.25 & 0 & 0.01 & 0.17 & -0.21 & 2.21 & 0.91 & 1.24\end{array}$

$\begin{array}{lllllllll}18.03 .2003 & 1.25 & 0 & 0.02 & -0.08 & 0.03 & -1.08 & 5.58 & 5.73\end{array}$

$\begin{array}{lllllllll}06.05 .2003 & 1.25 & 0 & 0.04 & 0.31 & 0.39 & -3.47 & -0.91 & 0.59\end{array}$

$\begin{array}{lllllllll}25.06 .2003 & 1 & -0.25 & 0.14 & -0.15 & -0.32 & 3.73 & 1.79 & 0.11\end{array}$

$\begin{array}{ccccccccc}12.08 .2003 & 1 & -0.25 & 0.14 & -0.15 & -0.32 & 3.73 & 1.79 & 0.11 \\ 16.09 .2003 & 1 & 0 & 0.00 & 0.00 & 0.32 & 0.48 & -0.87 & 0.18\end{array}$

$\begin{array}{lllllllll}16.09 .2003 & 1 & 0 & 0.01 & 0.09 & 0.14 & -3.33 & 3.67 & 4.93\end{array}$

$\begin{array}{lllllllll}28.10 .2003 & 1 & 0 & -0.01 & -0.02 & 0.71 & -0.85 & -2.55 & -0.54\end{array}$

$\begin{array}{lllllllll}09.12 .2003 & 1 & 0 & 0.00 & -0.16 & -1.01 & -0.43 & 2.04 & 0.71\end{array}$

$\begin{array}{ccccccccc}28.01 .2004 & 1 & 0 & 0.01 & -0.96 & -1.13 & 1.32 & 4.35 & 2.20\end{array}$

$\begin{array}{lllllllll}16.03 .2004 & 1 & 0 & 0.00 & -0.24 & 0.50 & -0.43 & -4.76 & -3.80\end{array}$

$\begin{array}{lllllllll}04.05 .2004 & 1 & 0 & -0.01 & 0.31 & -0.25 & 0.82 & 0.48 & 0.25\end{array}$

$\begin{array}{lllllllll}30.06 .2004 & 1.25 & 0.25 & -0.01 & 0.18 & -0.07 & 0.80 & -4.55 & -3.48\end{array}$

$\begin{array}{lllllllll}10.08 .2004 & 1.5 & 0.25 & 0.01 & -0.23 & -0.13 & -0.41 & 2.70 & 3.50\end{array}$

$\begin{array}{ccccccccc}21.09 .2004 & 1.75 & 0.25 & 0.00 & 0.00 & 0.21 & -0.88 & 0.00 & 0.34\end{array}$

$\begin{array}{lllllllll}10.11 .2004 & 2 & 0.25 & -0.01 & 0.13 & 0.15 & 0.81 & 0.57 & 0.39\end{array}$

$\begin{array}{lllllllll}14.12 .2004 & 2.25 & 0.25 & -0.01 & -0.12 & 0.14 & 0.40 & -1.82 & -1.40\end{array}$

$\begin{array}{lllllllll}02.02 .2005 & 2.5 & 0.25 & 0.00 & -0.13 & 0.08 & -1.21 & 1.80 & 2.10\end{array}$

$\begin{array}{lllllllll}22.03 .2005 & 2.75 & 0.25 & -0.02 & -0.51 & -0.79 & 1.10 & 3.89 & 1.49\end{array}$

$\begin{array}{lllllllll}03.05 .2005 & 3 & 0.25 & 0.00 & 0.45 & -0.10 & -1.15 & 1.86 & 1.97\end{array}$

$\begin{array}{lllllllll}30.06 .2005 & 3.25 & 0.25 & 0 & -0.5994 & -0.08267 & -1.30 & -1.18 & -1.62\end{array}$

$\begin{array}{ccccccccc}09.08 .2005 & 3.5 & 0.25 & 0 & 0.186408 & 0.170455 & -0.42 & 0.00 & 0.78\end{array}$ 23

FIG. 2. 


\section{REFERENCES}

[1] Bernanke, B. S., and K. N. Kuttner (2005). "What Explains the Stock Market's Reaction to Federal Reserve Policy?," Journal of Finance 60(3), 1221-1257.

[2] Campbell, J. Y., and J. Ammer (1993). "What Moves the Stock and Bond Markets? A Variance Decomposition for Long-Term Asset Returns", Journal of Finance 48(1), 3-37.

[3] Cochrane, J. H., and M. Piazzesi (2002). "The FED and Interest Rates - A HighFrequency Identification", American Economic Review 92(2), May 2002, 90-95.

[4] Demiralp, S., and O. Jorda (2004). "The Response of Term Rates to Fed Announcements", Journal of Money, Credit, and Banking 36, 387-405.

[5] Ellingsen, T., and U. Söderström (2001). "Monetary Policy and Market Interest Rates", American Economic Review 91(5), December 2001, 1594-1607.

[6] Ellingsen, T., and U. Söderström (2005). "Why Are Long Rates Sensitive to Monetary Policy?", Mimeo.

[7] Fleming, M. J., and M. Piazzesi (2005). "Monetary Policy Tick-by-Tick", Mimeo.

[8] Gürkaynak, R., B. Sack and E. Swanson (2005a). "Do Actions Speak Louder Than Words? The Response of Asset Prices to Monetary Policy Actions and Statements", International Journal of Central Banking 1(1), May 2005, 55-93.

[9] Gürkaynak, R., B. Sack and E. Swanson (2005b). "The Sensitivity of Long-Term Interest Rates to Economic News: Evidence and Implications for Macroeconomic Models", American Economic Review 95(1), March 2005, 425-36. 
[10] Kuttner, K. N. (2001). "Monetary Policy Surprises and Interest Rates: Evidence from the Fed Funds Futures Market", Journal of Monetary Economics 47(3), 523-544.

[11] Romer, D., and C. D. Romer (2000). "Federal Reserve Information and the Behavior of Interest Rates", American Economic Review 90 (3), 429-457. 
Table 1. Stock and Bond Market Comovements to Monetary Policy Surprises

\begin{tabular}{lcccc} 
& $\#$ obs & $b$ & $a$ & R-sq. \\
\hline All non-zero surprise observations & 116 & $0.09^{* *}$ & 0.02 & 0.05 \\
Surprise target increases & 70 & $0.19^{* *}$ & 0.00 & 0.08 \\
Surprise target decreases & 46 & 0.06 & 0.06 & 0.02 \\
Stock and bond prices up & 29 & $0.25^{* *}$ & $0.11^{* *}$ & 0.36 \\
Stock prices up bond prices down & 35 & $-0.13^{* *}$ & $-0.09^{* *}$ & 0.76 \\
Stock prices down bond prices up & 45 & -0.02 & $0.15^{* *}$ & 0.00 \\
Stock and bond prices down & 68 & $0.43^{* *}$ & -0.06 & 0.41
\end{tabular}

This table shows the number of observations (\# obs), estimated coefficients ( $a$ is the constant and $b$ is the slope coefficient), and R-squares from the seven regressions where the dependent (explanatory) variable is the 30-minute return of bond (stock) futures when FOMC decisions cause non-zero surprises. $*^{*}(*)$ means the rejection of the null hypothesis at $1 \%(5 \%)$ level that the estimated coefficient is zero. 
Table 2. Stock and Bond Price Reactions to Monetary Policy Surprises

\begin{tabular}{|c|c|c|c|}
\hline & $a$ & $b$ & R-sq. \\
\hline SP & $-0.095^{*}$ & $-4.274 * *$ & 0.345 \\
\hline se & 0.041 & 0.471 & \\
\hline TY & -0.004 & $-0.725 * *$ & 0.052 \\
\hline se & 0.021 & 0.249 & \\
\hline
\end{tabular}

This table shows the stock futures price reactions (SP) and bond futures price reactions (TY) to monetary policy surprises calculated on the basis of the federal funds futures appropriately rescaled by the number of the days left until the end of the current month. It also shows the estimated coefficients ( $a$ is the constant and $b$ is the slope coefficient), standard errors (se) and R-squares. The sample period spans from 1990 to $2007 .{ }^{* *}\left(^{*}\right)$ means the rejection of the null hypothesis at $1 \%$ $(5 \%)$ level that the estimated coefficient is zero. 
Table 3. Stock and Bond Market Reactions and Expectation Revisions

\begin{tabular}{|c|c|c|c|c|c|c|}
\hline \multirow[t]{7}{*}{ All FOMC dates } & Case & \# Obs & DEINFL & DERR & NDG day & NDG $30 \mathrm{~m}$ \\
\hline & either sp or ty flat & 4 & -0.85 & -0.21 & 0.33 & -0.18 \\
\hline & sp \& ty up & 16 & -1.04 & -0.11 & 1.49 & 0.54 \\
\hline & sp up, ty down & 6 & 4.05 & -0.52 & 0.67 & 0.60 \\
\hline & sp down, ty up & 18 & -0.87 & -0.16 & -0.40 & -0.57 \\
\hline & sp \& ty down & 19 & 0.78 & 0.60 & 0.43 & 0.15 \\
\hline & Mean & 63 & 0.05 & 0.05 & 0.48 & 0.07 \\
\hline Surprise & Case & \# Obs & DEINFL & DERR & NDG day & NDG $30 \mathrm{~m}$ \\
\hline \multirow[t]{6}{*}{ Increase Rates } & either sp or ty flat & 2 & -0.43 & -0.29 & 0.55 & -0.16 \\
\hline & sp \& ty up & 3 & -2.06 & 0.92 & 2.38 & 1.11 \\
\hline & sp up, ty down & 2 & 1.60 & 0.46 & 1.50 & 0.83 \\
\hline & sp down, ty up & 7 & -1.35 & 0.64 & -0.27 & 0.06 \\
\hline & sp \& ty down & 10 & 1.07 & 0.70 & 0.48 & 0.31 \\
\hline & Mean & 24 & -0.11 & 0.61 & 0.59 & 0.34 \\
\hline Surprise & Case & \# Obs & DEINFL & DERR & NDG day & NDG $30 \mathrm{~m}$ \\
\hline \multirow[t]{6}{*}{ Decrease Rates } & either sp or ty flat & 2 & -1.27 & -0.12 & 0.12 & -0.20 \\
\hline & sp \& ty up & 13 & -0.81 & -0.35 & 1.29 & 0.40 \\
\hline & sp up, ty down & 4 & 5.27 & -1.01 & 0.25 & 0.49 \\
\hline & sp down, ty up & 11 & -0.57 & -0.67 & -0.48 & -0.97 \\
\hline & sp \& ty down & 9 & 0.45 & 0.49 & 0.37 & -0.02 \\
\hline & Mean & 39 & 0.15 & -0.30 & 0.41 & -0.10 \\
\hline
\end{tabular}

This table shows the average percentage revisions in expectations on inflation (DEINFL), real interest rates (DERR) and net dividend growth (NDG "day" and "30m" mean respectively daily and 30minute intervals) conditional on the five cases representing the different joint reactions of stock and bond markets to (non-zero) monetary policy surprises. The case called "either sp or ty flat" refers to unchanged prices either on the stock or bond market. The case "sp \& ty up" ("sp \& ty down") refers to positive (negative) return on both markets. The case "sp up, ty down" ("sp down, ty up") refers to a positive (negative) stock return and negative (positive) bond return. Negative numbers are in bold. 
Table 4. Correlation Matrix between Asset Returns \& Value Drivers

\begin{tabular}{lcccc} 
& SP 30m & SP day & NDG & DERR \\
\hline SP 30m & 1 & & & \\
SP day & $0.70^{* *}$ & 1 & & \\
NDG & $0.38^{* *}$ & $0.55^{* *}$ & 1 & \\
DERR & -0.09 & -0.11 & $0.77^{* *}$ & 1 \\
& & & & \\
& TY 30m & TY day & DEINFL & DERR \\
\hline TY 30m & 1 & & & \\
TY day & $0.71^{* *}$ & 1 & & \\
DEINFL & $-0.43^{* *}$ & $-0.61^{* *}$ & 1 & \\
DERR & $-0.44^{* *}$ & $-0.67^{* *}$ & -0.09 & 1 \\
& & & & \\
& & & & \\
\hline US 30m & 1 & & & \\
US day & $0.66^{* *}$ & 1 & & \\
DEINFL & $-0.47^{* *}$ & $-0.59^{* *}$ & 1 & \\
DERR & $-0.41^{* *}$ & $-0.64^{* *}$ & -0.09 & 1
\end{tabular}

This table shows the correlation matrices between stock futures returns ("SP"), bond futures returns (either 10-year or 30-year US Treasury Notes denoted by "TY" and "US", respectively) and their value drivers, i.e. revisions on expected inflation (DEINFL), real interest rates (DERR) and net dividend growth (NDG). "30m" stands for 30-minute returns and "day" for daily returns. ${ }^{* *}\left(^{*}\right)$ means the rejection of the null hypothesis at $1 \%(5 \%)$ level that the correlation is equal zero. 
Table 5. Regressions between Asset Returns \& Value Drivers 10 Year U.S. Treasury Bonds Futures

Variance Decomposition

\begin{tabular}{lrrrrr} 
& & Const & DERR & DEINFL & R-sq. \\
\hline Coef & & 0.011 & -0.141 & & 0.446 \\
& se & 0.029 & 0.017 & & \\
& & & & & \\
Coef & & 0.014 & & -0.086 & 0.371 \\
& se & 0.031 & & 0.012 & \\
& & & & & \\
Coef & & 0.015 & -0.153 & -0.095 & 0.894 \\
& se & 0.013 & 0.007 & 0.005 & \\
\hline
\end{tabular}

\begin{tabular}{ccc} 
DERR & DEINFL & Residual \\
\hline $45 \%$ & & $55 \%$ \\
& & \\
& $37 \%$ & $63 \%$ \\
$53 \%$ & $45 \%$ & $2 \%$ \\
\hline
\end{tabular}

30 Year U.S. Treasury Bonds Futures

\begin{tabular}{|c|c|c|c|c|c|}
\hline \multirow{3}{*}{$\overline{\text { Coef }}$} & & Const & DERR & DEINFL & $\mathrm{R}$-sq. \\
\hline & & 0.020 & -0.188 & & \multirow[t]{2}{*}{0.410} \\
\hline & se & 0.041 & 0.024 & & \\
\hline \multirow[t]{2}{*}{ Coef } & & 0.024 & & -0.117 & \multirow[t]{2}{*}{0.350} \\
\hline & se & 0.043 & & 0.017 & \\
\hline \multirow[t]{2}{*}{ Coef } & & 0.025 & -0.205 & -0.129 & \multirow[t]{2}{*}{0.831} \\
\hline & $\mathrm{se}$ & 0.022 & 0.013 & 0.009 & \\
\hline
\end{tabular}

\begin{tabular}{ccc} 
DERR & DEINFL & Residual \\
\hline $41 \%$ & & $59 \%$ \\
& & \\
& $35 \%$ & $65 \%$ \\
$48 \%$ & $42 \%$ & $9 \%$ \\
\hline
\end{tabular}

S\&P 500 Index

\begin{tabular}{lrrrrr} 
& & Const & DERR & NDG & R-sq. \\
\hline Coef & & 0.336 & -0.082 & & 0.011 \\
& se & 0.141 & 0.083 & & \\
& & & & & \\
\multirow{2}{*}{ Coef } & & 0.217 & & 0.360 & 0.307 \\
& se & 0.120 & & 0.058 & \\
\hline
\end{tabular}

\begin{tabular}{ccc} 
DERR & NDG & Residual \\
\hline $1 \%$ & & $99 \%$ \\
& & \\
& $31 \%$ & $69 \%$ \\
\hline
\end{tabular}

This table shows the regression results where the dependent variable is the daily return of futures prices on the S\&P index, 10-year and 30-year US Treasury Notes. The explanatory variables are a constant, revisions in expectations on real interest rates ("DERR") and expected inflation ("DEINFL") for bonds, and on net dividend growth ("NDG") for stocks. The explanatory variables are used one after the other. On the right-hand side, the variance decomposition shows the contribution to the coefficient of determination of each variable. "se" means standard errors. 
Table 6. Correlation Matrix between Joint Stock and Bond Returns \& Value Drivers 30-minute Data

\begin{tabular}{lccccccc} 
& $\Delta \mathrm{sp} \Delta$ ty & $\Delta \mathrm{r}$ & $\Delta \mathrm{I}$ & $\Delta \mathrm{d}$ & $\Delta \mathrm{r} . \Delta \mathrm{I}$ & $\Delta \mathrm{I} . \Delta \mathrm{d}$ & $\Delta \mathrm{r} . \Delta \mathrm{d}$ \\
\hline$\Delta \mathrm{sp} \Delta$ ty & & & & & & & \\
$\Delta \mathrm{r}$ & 0.03 & & & & & & \\
$\Delta \mathrm{I}$ & $-0.52^{* *}$ & -0.09 & & & & & \\
$\Delta \mathrm{d}$ & -0.14 & $0.80^{* *}$ & 0.07 & & & & \\
$\Delta \mathrm{r} . \Delta \mathrm{I}$ & $-0.30^{* *}$ & 0.12 & $0.26^{* *}$ & 0.21 & & & \\
$\Delta \mathrm{I} . \Delta \mathrm{d}$ & $-0.79^{* *}$ & 0.07 & $0.59^{* *}$ & 0.32 & $0.65^{* *}$ & & \\
$\Delta \mathrm{r} . \Delta \mathrm{d}$ & -0.01 & 0.02 & 0.07 & 0.00 & -0.22 & -0.05 & \\
$\Delta \mathrm{r} . \Delta \mathrm{I} . \Delta \mathrm{d}$ & $-0.43^{* *}$ & -0.23 & 0.62 & -0.08 & 0.25 & $0.53^{* *}$ & -0.06 \\
\hline
\end{tabular}

\section{Daily Data}

\begin{tabular}{|c|c|c|c|c|c|c|c|}
\hline & $\Delta \mathrm{sp} \Delta$ ty & $\Delta \mathrm{r}$ & $\Delta \mathrm{I}$ & $\Delta \mathrm{d}$ & $\Delta \mathrm{r} . \Delta \mathrm{I}$ & $\Delta \mathrm{I} . \Delta \mathrm{d}$ & $\Delta \mathrm{r} . \Delta \mathrm{d}$ \\
\hline \multicolumn{8}{|l|}{$\Delta \mathrm{sp} \Delta$ ty } \\
\hline$\Delta \mathrm{r}$ & -0.02 & & & & & & \\
\hline$\Delta \mathrm{I}$ & $-0.57 * *$ & -0.09 & & & & & \\
\hline$\Delta \mathrm{d}$ & -0.12 & $0.77 * *$ & 0.05 & & & & \\
\hline$\Delta \mathrm{r} . \Delta \mathrm{I}$ & $-0.42 * *$ & 0.12 & $0.26^{* *}$ & 0.15 & & & \\
\hline$\Delta \mathrm{I} . \Delta \mathrm{d}$ & $-0.80 * *$ & 0.05 & $0.57 * *$ & 0.19 & $0.35 * *$ & & \\
\hline$\Delta \mathrm{r} . \Delta \mathrm{d}$ & -0.06 & $-0.23 *$ & 0.02 & -0.2 & 0.07 & -0.13 & \\
\hline$\Delta \mathrm{r} . \Delta \mathrm{I} . \Delta \mathrm{d}$ & $-0.38 * *$ & 0.13 & $0.31 * *$ & $0.25 *$ & 0.14 & $0.43 * *$ & -0.11 \\
\hline
\end{tabular}

This table shows the correlation matrices between the joint stock and bond futures returns (" $\Delta$ sp. $\Delta$ ty"), individual value drivers $(\Delta I, \Delta r$ and $\Delta d$ which means revisions in expected inflation, real interest rates and net dividend growth, respectively) and their combinations ( $\Delta I . \Delta r, \Delta r . \Delta \delta, \Delta \pi . \Delta \delta$ and $\Delta \pi . \Delta r . \Delta \delta$ ) based on 30-minute and daily time intervals. ${ }^{* *}\left(^{*}\right)$ means the rejection of the null hypothesis at $1 \%(5 \%)$ level that the correlation is equal zero. 
Table 7. Joint Reaction of Stock and Bond Prices

LS regression

\begin{tabular}{llllcl} 
& & & Const & DEINFL*NDG & R-sq. \\
\hline \multirow{2}{*}{$30 \mathrm{~min}$} & Coef & & 0.050 & -0.040 & 0.630 \\
& & se & 0.031 & 0.003 & \\
& & & & & \\
\multirow{2}{*}{ Daily } & Coef & & 0.038 & -0.065 & 0.638 \\
& & se & 0.049 & 0.005 & \\
\hline
\end{tabular}

\section{Probit Regression}

\begin{tabular}{llcccc} 
& & Const & Binary & R-sq. \\
\hline 30 min & Coef & & -0.674 & 0.517 & 0.029 \\
& & se & 0.182 & 0.288 & \\
& & & & & \\
\multirow{2}{*}{ Daily } & Coef & & -0.674 & 0.885 & 0.085 \\
& & se & 0.189 & 0.283 & \\
\hline
\end{tabular}

This table shows to what extent the joint revision of expected inflation and net dividend growth at monetary policy announcements can explain the joint reaction of stock and bond markets. On the upper part, the table shows the results of LS regressions where the explained variable is the intradaily ("30 min") or daily ("Daily") stock futures return multiplied by the simultaneous bond futures return, the explanatory variables is a constant ("Const") and the multiplication of the revision in expected inflation and net dividend growth ("DEINFL*NDG"). The lower part of the table shows the Probit regression where the dependent variable is equal 1 if stock return multiplied to bond return is positive, 0 otherwise, and the explanatory variable (called "Binary") has a binary value that is 1 if DEINFL*NDG is positive, zero otherwise. "R-sq." and "se" mean R-square coefficients and standard errors. 


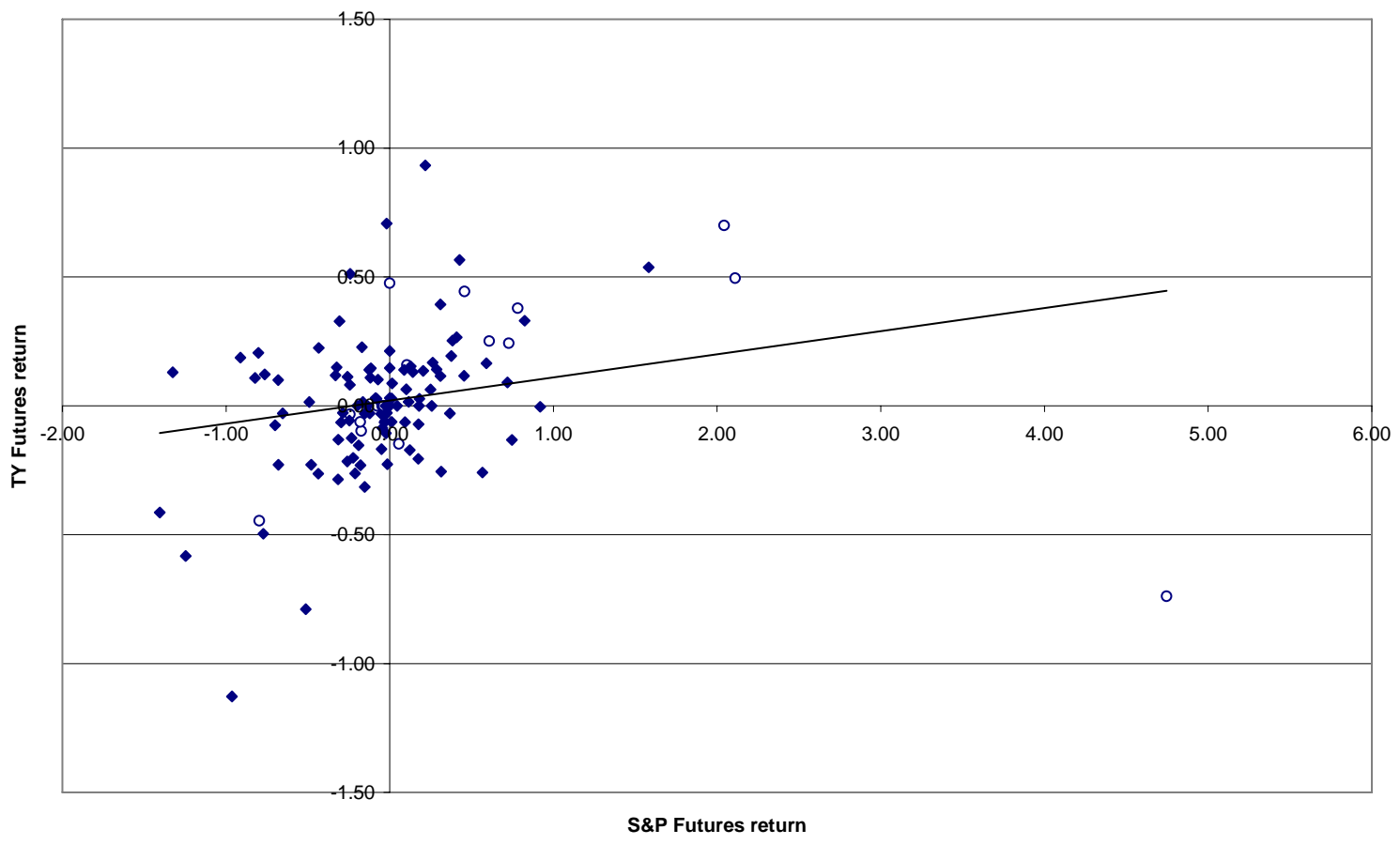

FIG. 3. This figure shows 30-minute returns in \% of futures contracts on S\&P 500 index (S\&P) and 10-Year US Treasury Notes (TY) over the period 1990-2007 when FOMC decisions releases are associated with a non-zero surprises. Circles with white background refer to inter-meeting decisions. 


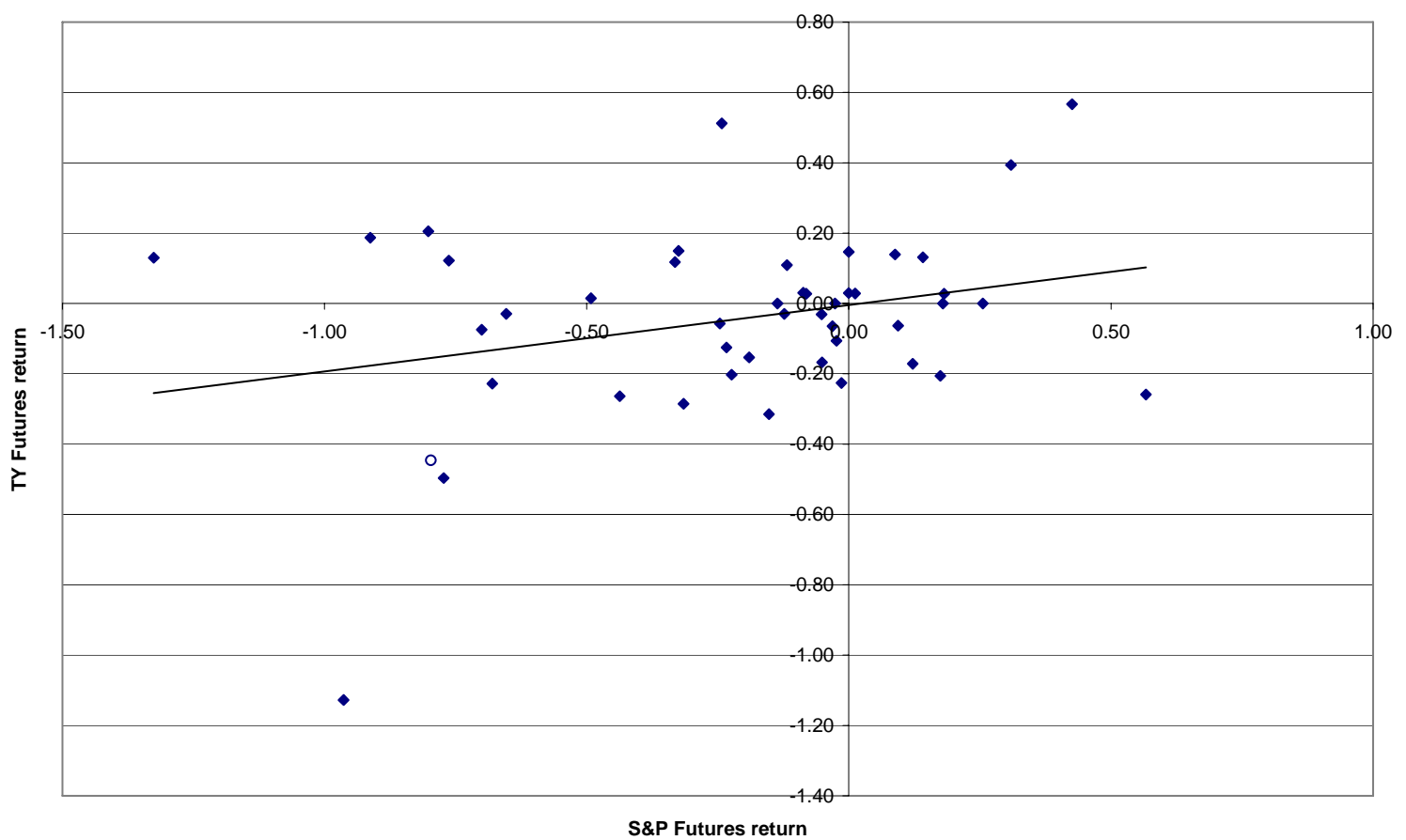

FIG. 4. 30-minute returns in \% of futures contracts on S\&P 500 index and 10-Year US Treasury Notes over the period 1990-2007 when FOMC decisions releases are associated with a suprise increase in interest rate target. Circles with white background refer to inter-meeting decisions. 


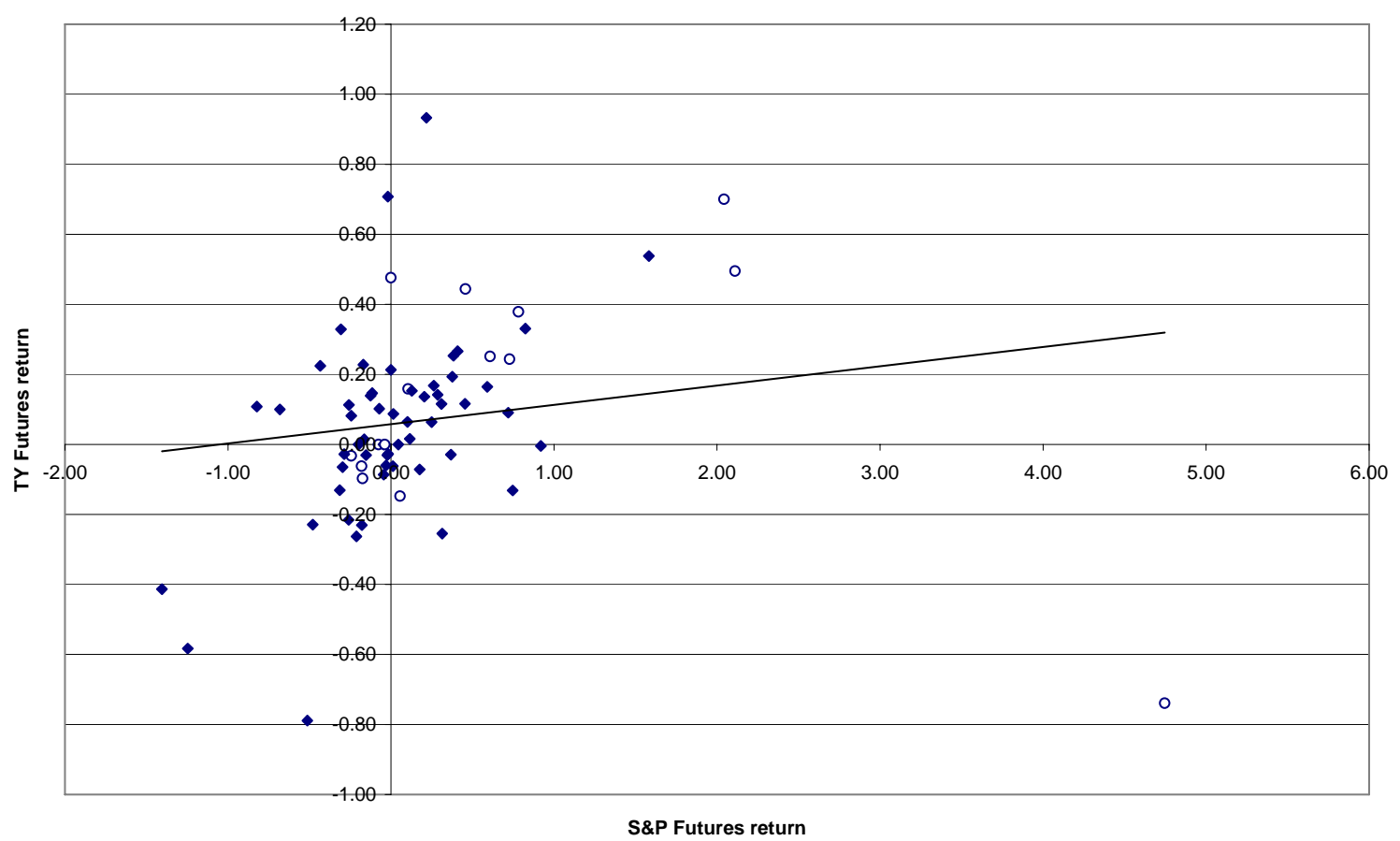

FIG. 5. 30-minute returns in \% of futures contracts on S\&P 500 index and 10-Year US Treasury Notes over the period 1990-2007 when FOMC decisions releases are associated with a suprise decrease in interest rate target. Circles with white background refer to inter-meeting decisions.

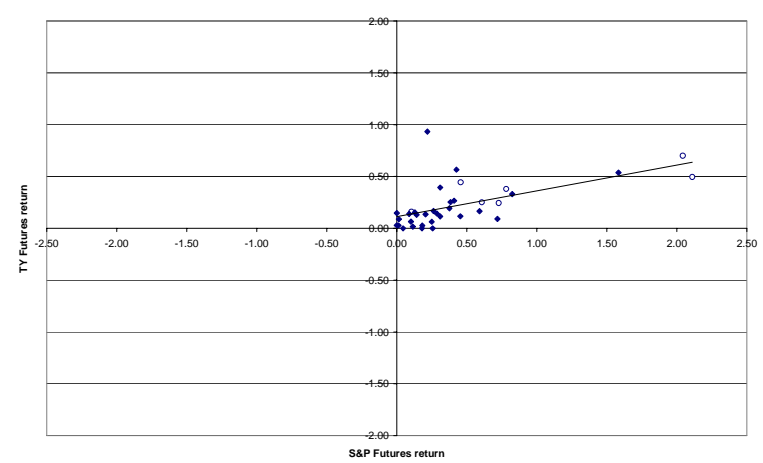

FIG. 6. Stock and bond futures prices react positively to monetary policy surprises. 


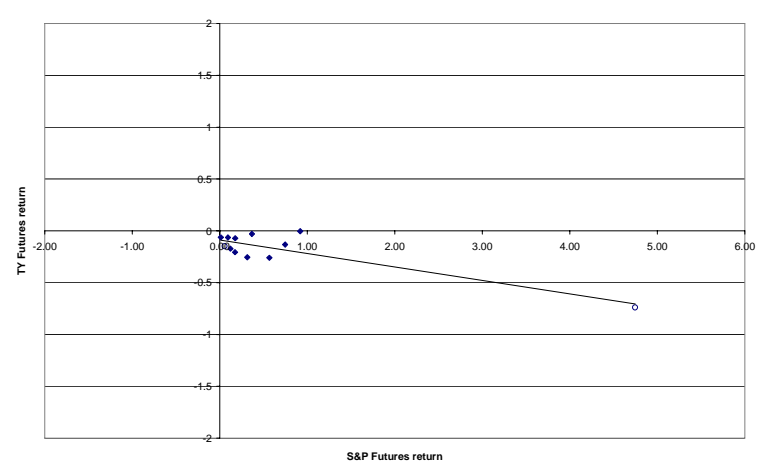

FIG. 7. Stock (bond) futures prices react positively (negatively) to monetary policy surprises.

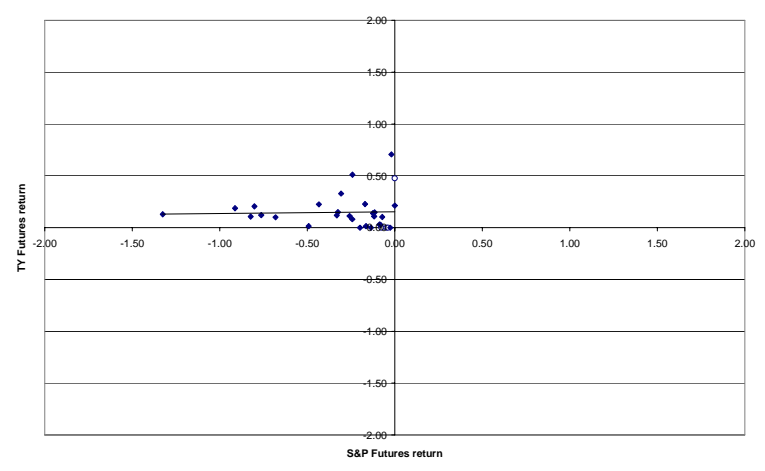

FIG. 8. Bond (stock) futures prices react positively (negatively) to monetary policy surprises.

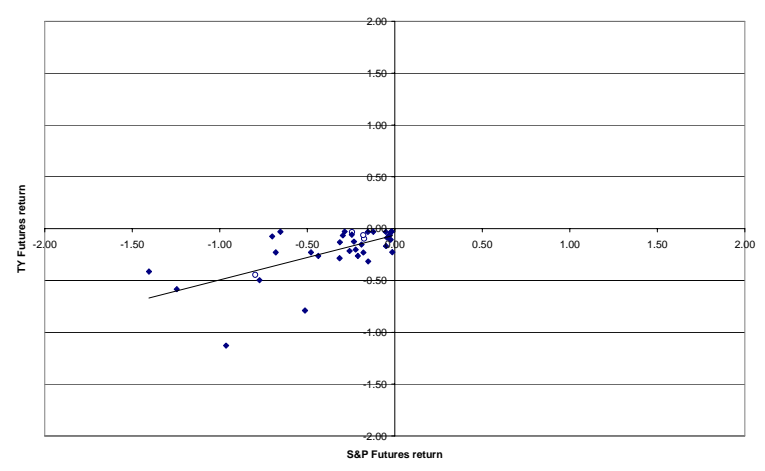

FIG. 9. Stock and bond futures prices react negatively to monetary policy surprises. 